\title{
Neurogenic Shock: Clinical Management and Particularities in an Emergency Room
}

\section{Choque neurogênico: manejo clínico e suas particularidades na sala de emergência}

\author{
Daniel Damiani ${ }^{1}$ \\ ${ }^{1}$ Department of Neuroscience, Universidade Anhembi Morumbi, \\ São Paulo, SP, Brazil \\ Arq Bras Neurocir 2018;37:196-205.
}

\begin{abstract}
Address for correspondence Daniel Damiani, MD, Instituto de Assistência Médica ao Servidor Público Estadual, Hospital do Servidor Público Estadual, Rua Pedro de Toledo, 1800, Vila Clementino, 04039000, São Paulo, SP, Brazil (e-mail: dani.neurocirurgia@gmail.com).
\end{abstract}

\author{
Abstract \\ Keywords \\ - neurogenic shock \\ - spinal shock \\ - intensive care \\ - spinal cord injury \\ - head trauma \\ - neurotrauma

\section{Resumo}

\section{Palavras-chave} \\ - choque neurogênico \\ - choque medular \\ - cuidados intensivos \\ - trauma raquimedular \\ - traumatismo \\ cranioencefálico \\ - neurotrauma
}

Neurogenic shock has a strong impact in traumatology. It is an important condition, associated with lesions in the neuraxis and can be medullar and/or cerebral. In the last years, its pathophysiology has been better understood, allowing a reduction in the morbimortality with more precise and efficacious interventions taking place in the emergency room. In this review article, the author presents the current aspects of the management of neurogenic shock, highlighting the neuroprotective measures that improve the outcome. Many pharmacologic interventions are still questionable and need more prospective studies to accurately assess their real value. The best moment for neurosurgical intervention is also debatable. Quite clearly, the initial proceedings in the emergency room are fundamental to guarantee the adequate conditions for neuroplasticity and neuronal rehabilitation.

O choque neurogênico tem um impacto considerável na traumatologia. Trata-se de uma condição importante, associada à lesão do neuroeixo, podendo ser medular e/ou cerebral. O conhecimento de sua fisiopatologia vem aumentando, permitindo assim a redução de sua morbimortalidade com intervenções mais precisas e eficazes já na sala de emergência. Neste artigo de revisão, o autor apresenta informações atuais sobre o manejo do choque neurogênico na sala de emergência, destacando medidas neuroprotetoras que impactem positivamente em sua evolução. Diversas medidas farmacológicas ainda são questionáveis, indicando a necessidade de novos estudos prospectivos e aleatórios para avaliar com precisão o seu valor. O momento adequado da intervenção neurocirúrgica também é discutível. Claramente, as medidas iniciais realizadas na sala de emergência são fundamentais para garantir condições adequadas à neuroplasticidade e reabilitação neuronal.

\section{Introduction}

Traumatic neuraxis injuries constitute one of the major causes of morbidity and mortality observed in the emergency room of trauma reference centers. The annual incidence varies between 15 and 52 cases per million people in the world. About $80 \%$ of the patients are young men between 15 and 35 years of age, with only $5 \%$ being children. Neurological functional impairment is often found, and the most common are tetraplegia (53\%) and paraplegia (42\%). The traumatic received

April 13, 2016

accepted

May 10, 2016

published online

October 25, 2016
DOI https://doi.org/

10.1055/s-0036-1584887. ISSN 0103-5355.
Copyright $\odot 2018$ by Thieme Revinter

Publicações Ltda, Rio de Janeiro, Brazil
License terms

() (1) $\Theta \circledast$ 
lesion can cause spinal cord shock, present frequently in lesions above T6, with neurogenic shock due to loss of sympathetic autonomic control. Classically, neurogenic shock has a triad: hypotension, bradycardia, and autonomic dysreflexia. ${ }^{1,2}$

Shock is the clinical expression of vascular inability to adapt to the demand for tissue oxygen. It is a frequent and serious condition that endangers the integrity of the noble organs, with a high mortality rate if not radically reversed. These patients require intensive care in the early stages of treatment. The diagnosis of shock is given by the clinical, hemodynamic and biochemical signs of the patient. Systolic blood pressure (SBP) of less than $90 \mathrm{~mm} \mathrm{Hg}$ and/or mean arterial pressure (MAP) of less than $70 \mathrm{~mm} \mathrm{Hg}$ are considered in shock of any origin. Other clinical signs include the presence of cold and sticky or even hot and dry skin, depending on the phase of the circulatory shock encountered; reduced urine output $(<0.5$ $\mathrm{mL} / \mathrm{kg} / \mathrm{h}$ ) representing renal hypoperfusion; and altered mental status, with confusion, drowsiness, dizziness, numbness, and coma. Laboratory abnormalities that are currently more significant for diagnosis and to some extent prognostic include hyperlactatemia (indicative of tissue anaerobiosis), increase in C-reactive protein and pro-calcitonin. Markers of lesions of noble organs are considered: creatinine, urea, bilirubins and clotting times. $^{3-5}$

Shock pathophysiology includes a variety of mechanisms: hypovolemia (loss of blood, diarrhea, vomiting, fever); cardiogenic factors (arrhythmias, myocardial ischemia, anomalous ventricular dilatation, valvulopathies); obstructive factors (cardiac tamponade, pericardial effusion, pulmonary thromboembolism, hypertensive pneumothorax) or distributive factors (to consider: inability to adequately control vascular tone for tissue metabolic demand, examples being anaphylaxis, sepsis and neurological lesions that compromise response of the autonomic sympathetic nervous system). The clinical history is a fundamental part for the diagnosis of the type of shock: traumas usually have the hypovolemic component and may be associated with neurogenic shock in the neuraxis or even cardiogenic lesions in the lesions of the thoracic structures. ${ }^{5}$

Proper management of neurogenic shock has been the subject of investigation. Stabilization of the spine, guarantee of adequate ventilation, volume resuscitation, and the use of vasopressors are fundamental steps for a better prognosis of the patient. The true effect of the available neuroprotective measures is not yet known: emergency surgical decompression is well indicated for patients with evident clinical worsening, but there is some doubt about the ideal moment of decompressive surgery in patients who arrive at the emergency room without evident worsening of their neurological condition. The contraindication to the use of opioids in the spinal cord injury also seems to be a consensus. The use of corticosteroids is contraindicated after a controlled and prospective high impact study (NASCIS III). The use of magnesium, riluzole, non-steroidal antiinflammatory drugs, estrogen, progesterone, minocycline, erythropoietin and induced hypothermia are still not well established in the treatment of neurogenic shock. ${ }^{6-8}$

\section{Objectives}

The author describes the current knowledge on the pathophysiology of neurogenic shock as well as its diagnostic criteria and its particularities in the clinical management in the emergency room.

\section{Methodology}

Bibliographic review article using as search tools: PubMed (National Institute of Health database), SciELO, LILACS and Cochrane. The keywords used were: neurogenic shock, spinal shock, medullar trauma, intensive care, neurotrauma, spinal cord injury and head trauma. The most recent articles were selected, taking into account their citations and their respective impacts.

\section{Development}

\section{Epidemiology}

The medullary lesions-represented by automobile accidents (48.8\%), injuries in contact sports (12\%), assaults and falls (40\%)-that present with neurogenic shock are important causes of cardiovascular dysfunction. Non-traumatic spinal cord injuries are represented by vascular diseases (25\%), tumors (25\%), inflammatory diseases (20\%) and spinal stenosis (19\%). Cardiovascular changes in neurogenic shock represent $40 \%$ of the causes of death of these patients in the acute phase (with their peak incidence up to day 4 days posttrauma), being represented by atrial fibrillation, atrial flutter, paroxysmal supraventricular tachycardia, cardiac insufficiency, atherosclerosis, ventricular tachycardia, cardiomyopathy, bradyarrhythmias, atrioventricular block and Takotsubo cardiomyopathy. Patients classified as A or B (full motor impairment) according to the American Spine Injury Association (ASIA) present bradycardia in almost $100 \%$ of cases and systolic hypotension in $60 \%$, requiring vasoactive drugs in $35 \%$ of cases. About 15 to $20 \%$ of these patients evolve with cardiorespiratory arrest. In patients classified as ASIA C and D, bradycardia occurs in 35 to $70 \%$ of cases, with rare cases of hypotension. Thoracolumbar spinal cord lesions develop bradycardia in $\sim 12$ to $35 \%$ of cases. The prevalence of lesions above $\mathrm{T} 6$ that may present dysautonomia varies between 48 and $90 \%$ of the cases, with deep venous thrombosis and pulmonary thromboembolism being potentially life-threatening complications, especially in the first 7 to 10 days after trauma. ${ }^{1,2,9-11}$

\section{Neuroanatomy and Pathophysiology}

Several supratentorial regions, such as the insula cortex, medial prefrontal cortex, hypothalamus, and brainstem nuclei, are responsible for autonomic functions. Didactically represented by the sympathetic and parasympathetic autonomic nervous system, these fibers control the vital signs, adapting them according to the environmental demand. Parasympathetic fibers reach the transverse colon through the vagus nerve, innervating the heart, bronchi, digestive tracts, and glands by long preganglionic fibers and short 
postganglionic fibers. There are no parasympathetic fibers directed to the peripheral blood vessels. The sympathetic autonomic nervous system, on the other hand, starts with preganglionic short fibers until a chain of paravertebral ganglia descends parallel to the thoracic and lumbar spinal cord (T1-L2), emitting long postganglionic fibers. These fibers, in turn, innervate the vast majority of viscera, including heart and vascular smooth muscle (-Fig. 1).

The concept of a two-stage injury was described around 1900 by Allen ${ }^{11}$. A first lesion occurs immediately after the trauma, followed by secondary lesions, triggered by the primary mechanical injury, resulting in microvascular damage, edema, demyelination, ischemia, excitotoxicity, electrolyte changes, free radical production, inflammation, and late apoptosis. The region immediately surrounding the injured site is considered as ischemic penumbra, with possible functional restoration (-Fig. 2). ${ }^{11}$ Kaptanoglu et al observed that melatonin, propofol, erythropoietin and thiopental may prevent lipid peroxidation soon after the injury in experimental models. Opioids are potentially lethal to injured cells, causing blockage of the microcirculation and impairing functional restoration by acting as neurotransmitters at kappa receptors. In several models, including phase I studies in humans, the use of naloxone (opioid antagonist) improves medullary functional recovery. ${ }^{12-14}$ Following the spinal cord trauma, in addition to the sensory and motor deficits observed, dysautonomia is typical of neurogenic shock. The loss of sympathetic autonomic control over the parasympathetic nervous system is responsible for the great majority of the symptoms that determine the neurogenic shock. Cardiovascular and respiratory disruption are the most feared ones. Parameters such as systemic blood pressure, heart rate, gland secretion, thermal control, bronchodilation and peripheral vascular resistance have been altered. During neurogenic shock, there is a predominance of the parasympathetic system over the sympathetic one, which can lead the patient to death. ${ }^{1,15}$

Hypotension as well as orthostatic hypotension improve over a few days or weeks, thanks to compensatory mechanisms that include: skeletal muscle activity, spasticity, increased muscle tone, resurgence of medullary sympathetic reflexes (readjusting catecholamine levels), and readaptation of the renin-angiotensin-aldosterone system. ${ }^{1}$

\section{Medullary Shock versus Neurogenic Shock}

During the acute phase following spinal cord trauma, massive sympathetic stimulation, mediated by $\alpha$-adrenergic receptors, occurs. Acutely, there is an increase in systemic blood pressure, bradycardia or reflected tachyarrhythmia. This acute sympathetic response occurs due to the release of noradrenaline and adrenaline from the medullary layer of the adrenal gland in response to trauma, as well as to the disconnection of sympathetic supraspinal neurons.
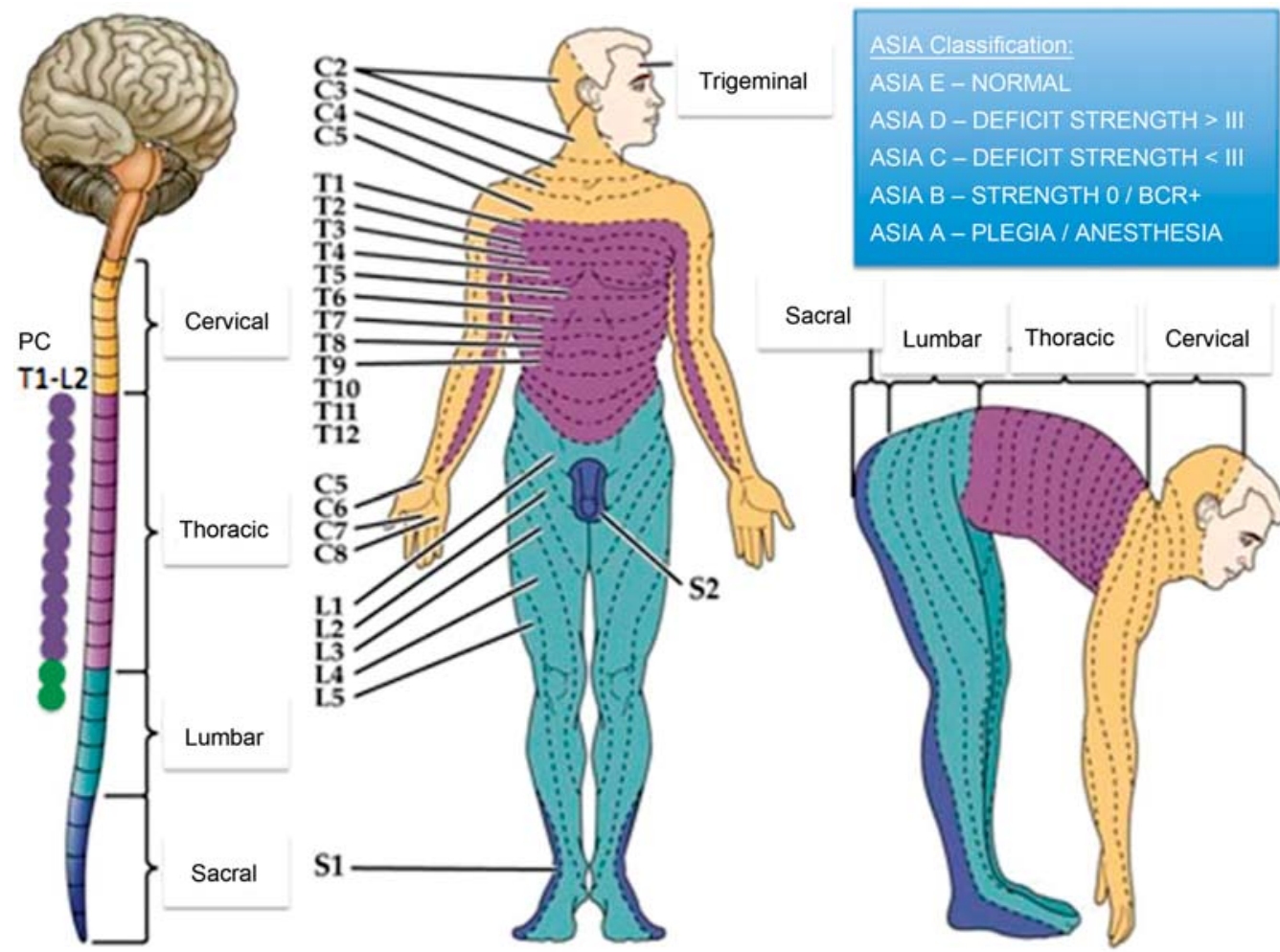

Sacral

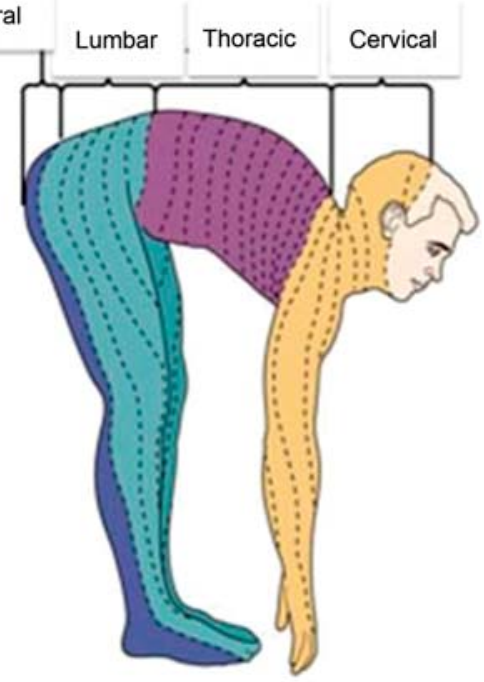

Fig. 1 Thoracic (T1-T12), lumbar (L1-L5) and sacral (S1-S2) segregated spinal segments (C1-C8), and their territories of sensory and motor innervation. It is very important in the initial neurological evaluation to delimit the sensory and motor level of the lesion by testing their respective territories. The figure also shows the classification currently used by ASIA to determine the intensity, severity, and prognosis of the neurological injury. The sensory level is determined by the protopathic touch and pain observed in the most caudal segment, present bilaterally, in both hemibodies. The motor level is determined by the myotomes tested: the Medical Research Council Scale for Muscle Strength is used to grade the present force: muscles with strength grade III, IV or V are considered normal. Abbreviations: ASIA, American Spinal Injury Association; $\mathrm{PC}$, chain of paravertebral ganglia; BCR +, presence of bulbocavernosus reflex. 


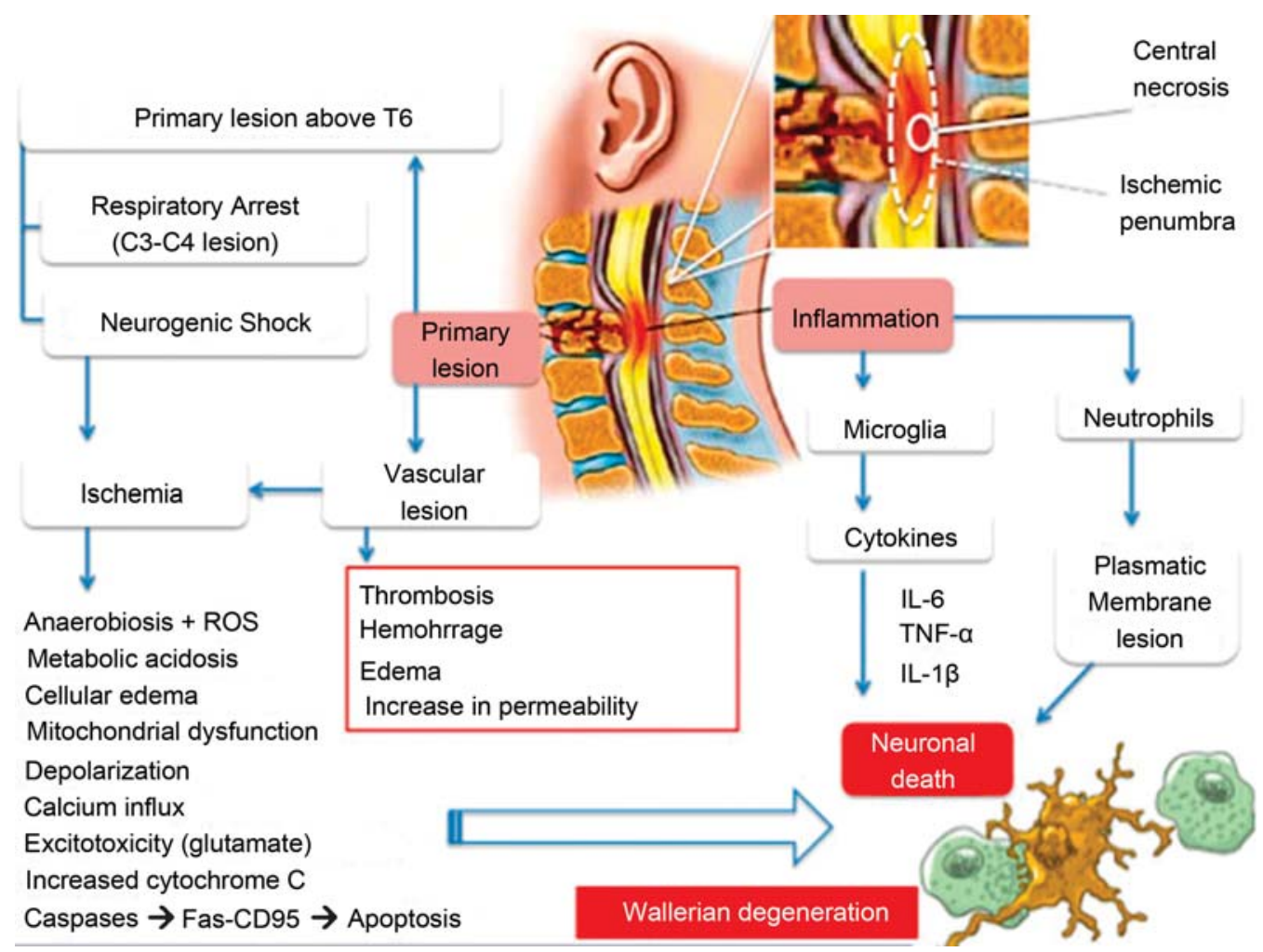

Fig. 2 Pathophysiology of spinal cord injury. At the time of injury there is cell death characterizing the primary lesion. Immediately after the primary lesion, the inflammatory process initiates reversible secondary lesions (penumbra zone) with release of cytokines, increased capillary permeability, edema, thrombosis and activation of microglia and neutrophils. In the presence of neurogenic shock, there is hypotension, bradycardia and poikilothermia due to sympathetic dysautonomia caused by trauma. Microvascular hypoperfusion accentuated by systolic hypotension initiates a cascade of responses to tissue anaerobic metabolism: metabolic acidosis, lactate formation, neoglucogenesis, mitochondrial dysfunction with cytochrome $C$ release, activation of caspases (induction of apoptosis), and anomalous cellular depolarization with calcium influx, activation of N-Methyl-D-Aspartate (NMDA) channels and cell death by excitotoxicity. The result of these cellular deaths is observed by Wallerian degeneration with functional loss. Adapted from Yilmaz, Kaptanoglu. World J Orthop 2015; 6 (1): 42-55.11

After 3 to 4 minutes, the parasympathetic nervous system predominates, with cutaneous vasodilatation, venodilatation, reduced venous return, systemic arterial hypotension, bradyarrhythmias with atrioventricular nodal blockade due to loss of sympathetic tone and absence of inotropic stimulus. At this point, patients also have hypothermia. Neurogenic shock, therefore, is caused by disconnection between sympathetic supraspinal centers and their target organs (high spinal cord injury), with systemic arterial hypotension, bradycardia, and peripheral vasodilation. The term medullary shock refers to the transient event that follows the trauma, with suspension of the medullary reflexes below the lesion level. Marrow shock was first described by Whytt ${ }^{1}$ in 1750 and introduced in the literature by Hall ${ }^{1}$ in 1841 . Spinal cord shock is characterized by sensory deficiency, flaccid paralysis, absence of spinal reflexes, and changes in thermoregulation below the level of the lesion. If the spinal cord injury is topographically elevated (cervical and/or thoracic), it may present with respiratory involvement, tetraplegia, anesthesia and neurogenic shock with associated ipsilateral Horner syndrome. In the lower thoracic lesions, there will usually be no respiratory compromise and/or neurogenic shock. Medullary shock may last for days or weeks, with an average of 4 to 12 weeks for resolution. Clinically, we will verify the return of the spinal functions with the reappearance of the bulbocavernosus reflex, as well as of the deep osteotendinous reflexes; some authors consider that the return of voluntary bladder control marks the end of the medullary shock phase. ${ }^{1}$

Ditunno describes the medullary shock in 4 phases: (1) areflexia or hyporeflexia, the first 24 hours; (2) return of some reflexes, 1 to 3 days; (3) early autonomic hyperreflexia, 4 days to 1 month; (4) spasticity, 1 to 12 months (-Fig. 3). ${ }^{16}$

\section{Clinical Presentation}

Lesions involving only the first three cervical segments require immediate ventilatory support for loss of the excitatory supraspinal drive, disrupting the function of the motor neurons of the phrenic nerve. In the lesions below $\mathrm{C} 3$, the patients present with symptoms of autonomic nervous system impairment, including the possibility of cardiorespiratory arrest a few minutes after the injury.

In the emergency room, the patient presents classically: flaccid paralysis, bradycardia and systolic arterial hypotension ( $\mathrm{SBp}<90 \mathrm{~mm} \mathrm{Hg}$ ) in orthostatic position. Inability to empty the bladder is also an important clinical feature. At this time, the emergency room should be aware of the possibility of neurogenic shock since, commonly, these symptoms are verified in patients who also present concomitant hemorrhagic and/or hypovolemic shock, who are 


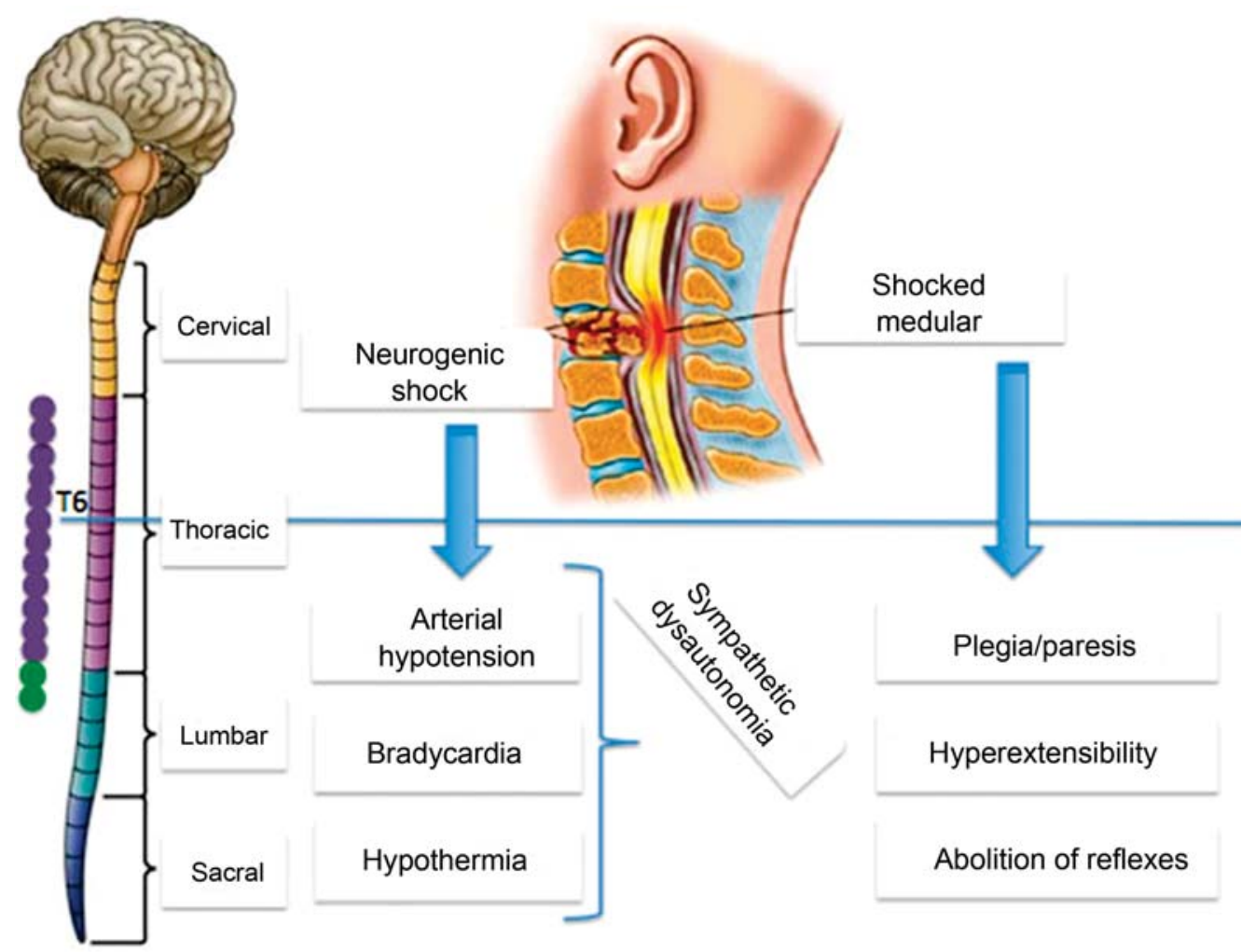

Fig. 3 Neurogenic shock is the result, in most cases, of the high spinal cord injury (above T6) that presents with medullary shock (plegia or paresis), hyperextensibility and hypo or deep osteotendinous and superficial cutaneous injury below the lesion. There are also reports of trauma to the lumbar spinal cord.

victims of polytrauma. ${ }^{17}$ In clinical practice, however, computed tomography is essential for diagnosis. According to data published in the Trauma Audit and Research Network database, neurogenic shock correlates with cervical lesions in $19.3 \%$ of cases, thoracic spine lesions in $7 \%$, and lumbar lesions in $3 \%$.

\section{Pressor Control and Syndrome of Inappropriate Antidiuretic Hormone (SIADH) Secretion}

Intensive monitoring of vital signs is necessary to maintain mean arterial pressure around 80 to $90 \mathrm{~mm} \mathrm{Hg}$, either with volume expansion or with vasoactive drugs. After surgical stabilization of the fracture, patients should be submitted to gradual decubitus elevations: an elevation of 10 degrees per day is recommended with constant monitoring of hemodynamic parameters. When the patient tolerates an elevation of 40 degrees, the wheelchair becomes an option for locomotion. Occasionally, orthostatic hypotension persists, requiring administration of fludrocortisone or $\alpha$-adrenergic agonists; the use of erythropoietin and desmopressin are adjunctive treatments in this context. ${ }^{1}$ Urinary volume is reduced in the first days after injury, most likely due to SIADH secretion. After the 3rd day, there is a very increased diuresis, reaching 5 to 6 L per day, erroneously associated with acute tubular necrosis resulting from the shock presented shortly after the trauma. Attention should be given to the volume of diuresis as well as to the patient's natremia. ${ }^{18}$

\section{Heart Arrhythmias}

The presence of cardiac arrhythmia is directly related to the severity of the neurological lesion. Sinus bradycardia is the most commonly observed arrhythmia after neurogenic shock and may occur within the first 2 to 3 weeks after neurological injury. Loss of supraspinal control causes persistent sinus bradycardia. However, not only has this arrhythmia been described, but also ventricular bradyarrhythmias, which can lead to cardiorespiratory arrest and the need to use transvenous pacemakers; atrial flares, supraventricular tachyarrhythmias, atrioventricular blocks, and atrial flutter are also related to dysautonomia. ${ }^{1}$

\section{Respiratory System}

Injuries to the rib cage are responsible for the reduction of thoracic expandability. However, as in neurogenic shock there is sympathetic deafferentation, any stimulus to the airways, such as aspiration (vagal stimulation), causes marked bradycardia, which can lead to cardiorespiratory arrest. When airway manipulation is required, the use of anticholinergics is recommended to reduce the risk of hemodynamic instability. ${ }^{19-21}$ Harvey Williams Cushing ${ }^{19}$, in 1903, described the connection between central nervous system damage and respiratory changes. In 1908, W.T. Shanahan ${ }^{20}$ describes 11 cases of acute pulmonary edema as a complication of seizures. Any injury to the brain or spinal cord can lead to pulmonary edema, with a higher mortality 
rate. There is a direct correlation between reduction of cerebral perfusion pressure (CPP) and reduction of the $\mathrm{PaO}_{2} / \mathrm{FiO}_{2}$ ratio. Increased intracranial pressure (ICP) is thought to cause parenchymal compression and ischemia, resulting in the release of catecholamines: the genesis of brain-induced pulmonary dysfunction, perpetuating an endothelial lesion that would result in increased capillary permeability. Venular adrenergic hyperresponsiveness also correlates with the genesis of neurogenic pulmonary edema, because it has $\alpha$ and $\beta$-adrenergic receptors. The areas considered "trigger" for the genesis of acute pulmonary edema are the hypothalamus, brainstem and spinal cord, with the areas A1 (ventrolateral medulla), A5 (upper medulla) being solitary tract nucleus and postremaining area of the floor of the ventricle IV. ${ }^{19,20}$

\section{Thermal Regulation}

A sympathetic autonomic nervous system injury creates a situation of inability to eliminate body heat through sweat. Patients with spinal cord injury associated with infectious conditions may present hyperthermia of 41 to $42^{\circ} \mathrm{C}$ without sweating, and frequently report a sensation of cold, exacerbated by the daily baths.

\section{Skin Care and Sensitivity}

Due to the loss of sensitivity caused by the interruption of afferent fibers as well as the hyperresponsiveness of peripheral adrenergic receptors, patients do not feel the lesions caused by decubitus; so, they should be moved at least every 4 hours. In infected patients or even with increased central temperature, a change of decubitus is recommended every 2 hours. $1,2,18$

\section{Genitourinary System}

In the initial phase of medullary shock, the bladder becomes atonic, flaccid and very distended (flaccid neurogenic bladder). After this initial phase of medullary shock (which may reach up to 3 to 4 months), patients who suffered cervical and/or thoracic spinal cord lesions present bladder medullary reflex, that is, spastic neurogenic bladder (a type of pyramidal tract lesion symptom) with inability to retain any urinary volume. In lesions to the lumbar and/or sacral spinal cord, the bladder is flaccid and atonic, representing a lesion of the inferior motor neuron. Current mortality from renal causes has decreased from 40 to $5 \%$ in the last decades, with intermittent bladder emptying maneuvers and appropriate treatment of urinary tract infections.

\section{Gastrointestinal System}

Gastric ulcers caused by metabolic stress are common. Paralytic ileus is clinically observed due to absence of hydro aerial sounds and inability to eliminate feces, which may last for $\sim 1$ to 2 weeks. Some precautions should be taken, such as avoiding any administration of solids and/or liquids during this period of paralytic ileus, due to the risk of vomiting and bronchoaspiration. Anal pains after the return of anal sphincter contraction reflect the imbalance between the sympathetic and parasympathetic autonomic control after spinal cord injury. ${ }^{15,18,22}$
Table 1 New parameters proposed by Mutschler et al (2014) to evaluate the need for replacement of hemoconcentration in emergency rooms where patients are polytraumatized with associated severe neurological damage

\begin{tabular}{|l|l|l|l|l|}
\hline Classification & Class I & Class II & Class III & Class IV \\
\hline Shock & Absent & Minimum & Moderate & Severe \\
\hline Base excess (BE) & $\begin{array}{l}0 \text { to } \\
(-2)\end{array}$ & $\begin{array}{l}>(-2) \text { to } \\
(-6)\end{array}$ & $\begin{array}{l}>(-6) \text { a } \\
(-10)\end{array}$ & $>(-10)$ \\
\hline Hemoconcentration & No & To consider & Yes & Yes \\
\hline
\end{tabular}

\section{Initial Patient Approach in the Emergency Room}

Early hemodynamic support is the therapeutic goal to avoid lesions of noble organs. The Advanced Trauma Life Support (ATLS) guidelines advocate the guarantee of a safe airway with previous stabilization of the cervical spine, thus maintaining the cervical collar throughout the evaluation and management of the patient. ${ }^{23-26}$ Classification of hypovolemic/hemorrhagic shock, as advocated by the ATLS, should be observed with caution in the presence of neurogenic shock. The classification currently proposed takes into account the Glasgow Coma Scale, heart rate, respiratory rate and systolic blood pressure values, known to be altered in neurogenic shock. Mutschler et al propose an alternative classification for these cases, considering the base excess (BE) values for indications of blood products in polytraumatized patients with associated severe brain and/or medullary lesions. The BE values reflect the hypovolemia status of these patients at the time of their admission to the emergency room ( - Table 1$){ }^{27,28}$

\section{Ventilation Support}

The administration of oxygen should be initiated immediately in patients in shock, so that there is adequate supply to the tissues as well as the microcirculation, also preventing pulmonary hypertension. Pulse oximetry has numerous limitations and often does not reveal the actual situation of the patient due to the present peripheral vasoconstriction; thus, arterial blood gas analysis is fundamental for the evaluation of the actual metabolic parameters of that patient. The persistence of hypoxemia, dyspnea, lowering of consciousness level, ventilatory accessory muscle fatigue, acidosis and persistent cyanosis are indicative of orotracheal intubation with mechanical ventilation (MV). ${ }^{5}$ However, orotracheal intubation with laryngoscopy and tracheal stimulation induces bradycardia due to vagovagal reflexes, and may lead to cardiorespiratory arrest, especially in hypoxemic patients. In situations of neurogenic shock, there is no sympathetic response opposing the reflex, and the use of atropine is indicated during the procedure. ${ }^{1}$ The hypotension often observed during and shortly after the invasive ventilation procedures is due to the hypovolemia of the patient with sudden reduction venous return and alteration of intrathoracic pressure by MV; the use of sedatives and hypnotics should be done in the smallest dose possible, reducing this frequently observed hypotensive effect. ${ }^{5}$ The use of succinylcholine during orotracheal intubation should be avoided in patients with neurogenic shock: this depolarizing neuromuscular blocker may induce 
cardiorespiratory arrest and hypokalemia due to hypersensitivity of the membranes of muscle cells. The use of narcotic analgesics and anticholinergics should be restricted to the smallest dose possible. ${ }^{1}$ The use of opioids in the first 7 days after trauma is known to impair motor medullary rehabilitation and lead to the formation of hypersensitive fibers responsible for neuropathic pain. ${ }^{29}$ Resuscitation to restabilize the microcirculation perfusion is the initial goal in the treatment of shock. Often a central vascular access allows a more effective response. $^{5}$ The mnemonic VIP used by the Americans alludes to the initial concerns about the patient in shock: $\mathrm{V}$ (ventilatory support), I (infusion-resuscitation with fluids) and P (pump administration of vasoactive drugs). Infusion of fluids should taken into account: the type of fluid to be administered (crystalloid solutions are the first options, colloids are in the background due to their cost), indication and availability, not significantly altering the clinical outcome; the rate of infusion (should not exceed 300 to $500 \mathrm{~mL}$ over a period of 20 to 30 minutes). The goal of volume replacement is to increase $\mathrm{SBP}$ ( $\leq 120 \mathrm{~mm} \mathrm{Hg}$ ), urinary output greater $>0.5 \mathrm{~mL} / \mathrm{kg} / \mathrm{h}$, central venous pressure (CVP) between 8 and $12 \mathrm{~mm} \mathrm{Hg}$ and venous oxygen saturation (superior vena cava) of $70 \%$. The concept of permissive hypotension cannot be considered in the presence of neurological injury. Volume caution should be taken and, if there are signs of overload, the use of vasopressors is indicated. 5,30,31 In patients with neurogenic shock who remain hypotensive and bradycardic (cardiac frequency (CF) $<60 \mathrm{bpm}$ ), administration of atropine ( 0.5 to $2 \mathrm{mg}$ per hour) in continuous infusion should be considered in combination with catecholamines. ${ }^{1,2}$ Adrenergic agonists are the first choice of vasoactive drugs in shock, since their high potency and rapid onset with short half-life facilitate their adjustment. Noradrenaline is the vasopressor of choice, possessing predominantly $\alpha$ adrenergic properties (vasoconstriction and increased peripheral vascular resistance) associated with modest $\beta$-adrenergic activation, aiding in cardiac function. Its administration results in increased SBP with almost no interference in heart rate. The recommended dose ranges from 0.1 to $2 \mathrm{mcg} / \mathrm{kg} / \mathrm{min}$. Low-dose dopamine ( 5 to $10 \mathrm{mcg} / \mathrm{kg} / \mathrm{min}$ ) is a predominantly $\beta$-adrenergic agonist, but at high doses $(>10 \mathrm{mcg} / \mathrm{kg} / \mathrm{min}$ ) it is $\alpha$-adrenergic. However, the $\alpha$-adrenergic effect of dopamine is poor compared with noradrenaline. The doses formerly described as nephroprotective are no longer used, no further doses of dopamine of less than $5 \mathrm{mcg} / \mathrm{kg} / \mathrm{min}$ are used for this purpose. Its interference in the hypothalamic-hypophyseal axis, with prolactin increase and immunosuppressive effect, contraindicates its use. Randomized, double-blind, placebo-controlled trials show that dopamine has no benefit when compared with first-line vasopressors, such as norepinephrine and adrenaline and is at increased risk for cardiac arrhythmias. Adrenalin at low doses is a potent $\beta$-adrenergic agonist, being $\alpha$-adrenergic at higher doses. Noradrenaline is preferred due to its lower arrhythmogenic effect when compared with adrenaline, the latter being a second-line agent.

In the hyperkinetic forms of neurogenic shock, patients develop vasopressin deficiency and, at relatively low doses (1 to $4 \mathrm{IU} / \mathrm{h}$ ), they have an excellent response to blood pressure control. The half-life of vasopressin is short, of a few minutes, with terlipressin (its analogue) being a second option to be considered in neurogenic shock. ${ }^{5}$

In patients with signs of cardiac failure associated with shock, some inotropic agents are good options for being associated with first-line drugs. Dobutamine is a potent $\beta$ adrenergic agonist with less interference in heart rate compared with isoproterenol (pure $\beta$-agonist). The usual dose of dobutamine is 1 to $20 \mathrm{mcg} / \mathrm{kg} / \mathrm{min}$, thus increasing the capillary perfusion regardless of its systemic effects. ${ }^{32}$

The class of drugs that act as calcium sensitizers, such as levosimendan, acts primarily to facilitate the binding of troponin $C$ by making more calcium available to the myocytes. However, these drugs also act on vascular smooth muscle as vasodilators by opening the sensitive adenosine triphosphatase (ATPase) potassium channels, limiting their use in shock states. $^{5}$ Persistent bradyarrhythmia, found in neurogenic shock can be reversed with administration of dopamine in continuous infusion pump (first-line drug), followed by other options such as: atropine and transcutaneous pacemaker, the latter being indicated only in the absence of a response to dopamine. Transvenous pacemakers are reserved for persistent long-term bradyarrhythmias. Some studies consider the use of aminophylline or any other methylxanthine as good alternatives to episodic bradycardia. ${ }^{1}$

Neurocardiogenic pulmonary edema has two forms of presentation: (1) early, triggered a few minutes to hours after the trauma; (2), occurs 12 to 24 hours after the trauma. In both cases, the patient suddenly becomes dyspneic, tachypneic and hypoxemic in a few minutes, with rosy and foamy sputum associated with crepitant rales. The patient may become febrile, tachycardic and hypertensive with leukocytosis. Chest X-ray examination evidence bilaterally opaque infiltrates consistent with acute respiratory distress syndrome (ARDS). The condition resolves spontaneously within 24 to 48 hours, provided the PIC is controlled. In the emergency room, the differentiation between cardiogenic and non-cardiogenic pulmonary edema is fundamental: non-cardiogenic edemas benefit from pharmacological interferences in the autonomic sympathetic nervous system (that is $\alpha$-adrenergic blockers, such as chlorpromazine and phentolamine), recommending that, in those cases, serum catecholamines are dosed. ${ }^{19-21}$ Protective orotracheal intubation includes the use of tidal volume between 6 and $8 \mathrm{~mL} /$ $\mathrm{kg}$ with positive end expiratory pressure (PEEP) $>3 \mathrm{cmH}_{2} \mathrm{O}$, and early extubation should be done as soon as Glasgow score is higher than $10 .^{19,20,33-35}$

Prophylaxis in cases of deep venous thrombosis as well as of pulmonary thromboembolism is already mandatory in the initial clinical management of the patient. Non-pharmacological strategies include the periodic mobilization of the patient in the bed, the use of pneumatic compression stockings and intensive therapy. Pharmacological therapies include the use of oral or parenteral anticoagulants. The use of low molecular weight heparin is superior when compared with unfractionated heparin, and with a lower risk of bleeding. As soon as possible, parenteral anticoagulant therapy should be replaced with oral. In patients with absolute contraindications to the use of anticoagulants, the use of vena cava filters should be considered. ${ }^{1}$ 


\section{Priorities of the Patient in Shock and Therapeutic Objectives}

In essence, there are four phases in the treatment of the patient in shock: (1) salvage phase: the aim is to regularize the patient's blood pressure to the minimum necessary to ensure adequate tissue perfusion associated with the regularization of myocardial function for this minimum perfusion; monitoring is minimal, often restricted to central venous and/or arterial catheters; measures to ensure good ventilation, volume restoration, introduction of vasoactive drugs and good emergency surgical procedures are essential to ensure survival; (2) adequacy phase: optimized measures for adequate tissue oxygenation; control of inflammatory processes, mitochondrial dysfunctions and activation of caspases; the measurements of venous oxygen saturation $\left(\mathrm{SvO}_{2}\right)$ and lactatemia help in the conducts; (3) stabilization phase: preoccupation with multiple organ dysfunction after hemodynamic stabilization; (4) weaning phase: general clinical improvement of the patient, with the possibility of gradual and progressive weaning of MV, sedation and vasoactive drugs. ${ }^{5,26,36}$

\section{Neurosurgical intervention}

Furlan et al conducted a systematic review of 22 clinical studies evaluating the safety, benefit, viability and efficacy of early neurosurgical intervention in medullary trauma patients to stabilize and align their vertebral columns by spinal cord decompression. Some studies showed no difference between early surgery (up to 72 hours after trauma) and late surgery (after clinical stabilization). However, other series were in favor of early intervention, with less time required for the recovery of spinal functions as well as for hospital stay. Cengiz et al observed in a randomized controlled trial that early surgery significantly improves the ASIA score in the early and late postoperative periods by reducing secondary insults caused by the injury. Patients submitted to early intervention had ASIA scores improved in $83.3 \%$ of the cases, while those submitted to late intervention showed an improvement of only 26.6\%. For patients with evident neurological worsening, immediate neurosurgical decompression is indicated. ${ }^{11,37,38}$

\section{Therapeutic Perspectives}

As the knowledge of the physiopathological mechanisms of spinal cord trauma increases, including neurogenic shock and spinal cord injury, new therapeutic strategies are proposed to optimize spinal recovery. Clinical and experimental evidence shows that the mechanism of medullary recovery undergoes neuroplasticity, with dendritic and axonal budding. Physical and electrical stimuli are known to increase the production of brain-derived neurotrophic factor (BDNF) and 3'-5'-cyclic adenosine monophosphate (cAMP), and act directly on the neuroplasticity of the central and peripheral nervous systems. It is currently speculated that chondroitin sulfate proteoglycans (CSPs), the main constituents of the extracellular matrix of the nervous system, would play a key role in the process of spinal regeneration. These matrices of CSPs would act as shrouds for neuronal growth, being inhibitors of the functional restoration of the spinal cord. In this context, Bradbury et $\mathrm{al}^{39}$ synthesized a bacterial enzyme called chondroitinase $A B C$ (chABC) and administered it intrathecally, observing that the corticospinal pathways no longer presented retraction after the lesions and also facilitated the budding with formations of collateral networks in the lesion area. However, as a side effect, they observed that there was formation of calcium gated related peptide (CGRP)-dependent neural networks, related to hyperalgesia and allodynia. Another experimental line takes into account that NOGO-A glycoprotein blockers would facilitate budding as well as neuronal reconnections after injury. AntiNOGO-A or IN-1 monoclonal antibodies are promising. Finally, neurotrophins increase the capacity of neuroplasticity at the site of the lesion, and they are easily administrated through an adenovirus that, by retrograde transport, reaches the lesion site with the least amount of trauma. The neurotrophins under study include: NT3, NGF, BDNF and Peg-BDNF. ${ }^{39,40}$

Methylprednisolone (synthetic glucocorticoid), used in the past 30 years to reduce medullary and cerebral edema, is outlawed. The results of three large prospective, multicenter, randomized, double-blind, placebo-controlled studies-National Acute Spinal Cord Injury Studies (NASCIS) I, II and III-revealed no difference in the long term between groups receiving methylprednisolone and the placebo group, with an aggravating factor: the groups that received methylprednisolone had higher mortality rates due to infections, pulmonary embolisms and severe pneumonia with septicemia. ${ }^{6-8,41}$ Some drugs have already been tested and present controversial results in terms of neuroprotection to spinal cord injuries (with no neuroprotective effect), estrogen and progesterone (both without any beneficial effect), magnesium (seems to have some beneficial effect), minocycline, erythropoietin and induced hypothermia (all with controversial results), anti-CD11d antibody (integrinbinding agent CD11d-CD18-seems to have effect on the reduction of the migration of neutrophils and macrophages to the perilesional penumbra, reduction of allodynia and dysautonomia, with increased dendritic and axonal budding). ${ }^{11-14,42,43}$

\section{Conclusion}

The diagnosis of spinal shock often poses a challenge to the emergency room team. Severe polytrauma patients are hypotensive, hypovolemic and hypothermic, in principle due to hypovolemia due to hemorrhage. The ATLS protocol recommends performing the basic measures in the primary exam that should not be neglected: stabilization of the cervical spine is the first step, in general, in all polytrauma patients. Once adequate volume replacement has been achieved, maintenance of hypotension with bradycardia and adequate peripheral perfusion, with cranial and/or spinal cord injury, should indicate the possible presence of neurogenic shock. The presence of neurological lesions remains an absolute contraindication to permissive hypotension, and its SBP should be $\leq 120 \mathrm{~mm} \mathrm{Hg}$. The management of neurogenic shock has some peculiarities that must be considered: the revision of cardiac arrhythmias (dopamine, atropine and transcutaneous pacemaker), which can lead to sudden death; management of the airways (protective MV) avoiding the vasovagal discharge and the use of neuromuscular 
paralyzers; intensive hydroelectrolytic and infectious control; use of restricted opiates at the lowest possible dose due to their interference in medullary recovery; early use of vasoactive drugs avoiding the precipitation of neurogenic pulmonary edema; prophylaxis to pressure ulcers and deep venous thrombosis; gastric protection; protection to perilesional ischemic penumbra zone; and evaluation of the indication of neurosurgical decompression. These are the particularities that define the prognosis of the patient.

\section{References}

1 Popa C, Popa F, Grigorean VT, et al. Vascular dysfunctions following spinal cord injury. J Med Life 2010;3(03):275-285

2 Grigorean VT, Sandu AM, Popescu M, et al. Cardiac dysfunctions following spinal cord injury. J Med Life 2009;2(02):133-145

3 Furlan JC, Fehlings MG. Cardiovascular complications after acute spinal cord injury: pathophysiology, diagnosis, and management. Neurosurg Focus 2008;25(05):E13

4 Casha S, Christie S. A systematic review of intensive cardiopulmonary management after spinal cord injury. J Neurotrauma 2011;28(08):1479-1495

5 Vincent JL, De Backer D. Circulatory shock. N Engl J Med 2013;369 (18):1726-1734

6 Coleman WP, Benzel D, Cahill DW, et al. A critical appraisal of the reporting of the National Acute Spinal Cord Injury Studies (II and III) of methylprednisolone in acute spinal cord injury. J Spinal Disord 2000;13(03):185-199

7 Bracken MB, Shepard MJ, Holford TR, et al. Administration of methylprednisolone for 24 or 48 hours or tirilazad mesylate for 48 hours in the treatment of acute spinal cord injury. Results of the Third National Acute Spinal Cord Injury Randomized Controlled Trial. National Acute Spinal Cord Injury Study. JAMA 1997; 277(20):1597-1604

8 Hurlbert RJ. Methylprednisolone for acute spinal cord injury: an inappropriate standard of care. J Neurosurg 2000;93(1, Suppl)1-7

9 Hector SM, Biering-Sørensen T, Krassioukov A, Biering-Sørensen F. Cardiac arrhythmias associated with spinal cord injury. J Spinal Cord Med 2013;36(06):591-599

10 Krishna V, Andrews H, Varma A, Mintzer J, Kindy MS, Guest J. Spinal cord injury: how can we improve the classification and quantification of its severity and prognosis? J Neurotrauma 2014; 31(03):215-227

11 Yılmaz T, Kaptanoğlu E. Current and future medical therapeutic strategies for the functional repair of spinal cord injury. World J Orthop 2015;6(01):42-55

12 Kaptanoglu E, Sen S, Beskonakli E, et al. Antioxidant actions and early ultrastructural findings of thiopental and propofol in experimental spinal cord injury. J Neurosurg Anesthesiol 2002; 14(02):114-122

13 Kaptanoglu E, Tuncel M, Palaoglu S, Konan A, Demirpençe E, Kilinç $\mathrm{K}$. Comparison of the effects of melatonin and methylprednisolone in experimental spinal cord injury. J Neurosurg 2000;93(01, Suppl)77-84

14 Kaptanoglu E, Solaroglu I, Okutan O, Surucu HS, Akbiyik F, Beskonakli E. Erythropoietin exerts neuroprotection after acute spinal cord injury in rats: effect on lipid peroxidation and early ultrastructural findings. Neurosurg Rev 2004;27(02):113-120

15 Hagen EM. Acute complications of spinal cord injuries. World J Orthop 2015;6(01):17-23

16 Ditunno JF, Little JW, Tessler A, Burns AS. Spinal shock revisited: a four-phase model. Spinal Cord 2004;42(07):383-395

17 Guly HR, Bouamra O, Lecky FE; Trauma Audit and Research Network. The incidence of neurogenic shock in patients with isolated spinal cord injury in the emergency department. Resuscitation 2008;76(01):57-62

18 Karlsson AK. Autonomic dysfunction in spinal cord injury: clinical presentation of symptoms and signs. Prog Brain Res 2006;152:1-8

19 Davison DL, Terek M, Chawla LS. Neurogenic pulmonary edema. Crit Care 2012;16(02):212-219

20 Davison DL, Chawla LS, Selassie L, Tevar R, Junker C, Seneff MG. Neurogenic pulmonary edema: successful treatment with IV phentolamine. Chest 2012;141(03):793-795

21 Mrozek S, Constantin JM, Geeraerts T. Brain-lung crosstalk: Implications for neurocritical care patients. World J Crit Care Med 2015;4(03):163-178

22 Summers RL, Baker SD, Sterling SA, Porter JM, Jones AE. Characterization of the spectrum of hemodynamic profiles in trauma patients with acute neurogenic shock. J Crit Care 2013;28(04): 531.e1-531.e5

23 Kool DR, Blickman JG. Advanced Trauma Life Support. ABCDE from a radiological point of view. Emerg Radiol 2007;14(03):135-141

24 Tee JW, Chan CHP, Fitzgerald MCB, Liew SM, Rosenfeld JV. Epidemiological trends of spine trauma: an Australian level 1 trauma centre study. Global Spine J 2013;3(02):75-84

25 Sundstrøm T, Asbjørnsen H, Habiba S, Sunde GA, Wester K. Prehospital use of cervical collars in trauma patients: a critical review. J Neurotrauma 2014;31(06):531-540

26 Chak Wah K, Wai Man C, Janet Yuen Ha W, Lai V, Kit Shing John W. Evolving frontiers in severe polytrauma management - refining the essential principles. Malays J Med Sci 2013;20(01):1-12

27 Mutschler M, Nienaber U, Wafaisade A, et al; TraumaRegister DGU®. The impact of severe traumatic brain injury on a novel base deficit- based classification of hypovolemic shock. Scand J Trauma Resusc Emerg Med 2014;22:28-34

28 Mutschler M, Nienaber U, Brockamp T, et al; TraumaRegister DGU. A critical reappraisal of the ATLS classification of hypovolaemic shock: does it really reflect clinical reality? Resuscitation 2013;84 (03):309-313

29 Woller SA, Hook MA. Opioid administration following spinal cord injury: implications for pain and locomotor recovery. Exp Neurol 2013;247:328-341

30 Myburgh JA, Mythen MG. Resuscitation fluids. N Engl J Med 2013; 369(13):1243-1251

31 Chatrath V, Khetarpal R, Ahuja J. Fluid management in patients with trauma: Restrictive versus liberal approach. J Anaesthesiol Clin Pharmacol 2015;31(03):308-316

32 De Backer D, Creteur J, Dubois MJ, et al. The effects of dobutamine on microcirculatory alterations in patients with septic shock are independent of its systemic effects. Crit Care Med 2006;34(02): 403-408

33 Adams HP Jr, del Zoppo G, Alberts MJ, et al; American Heart Association/American Stroke Association Stroke Council; American Heart Association/American Stroke Association Clinical Cardiology Council; American Heart Association/American Stroke Association Cardiovascular Radiology and Intervention Council; Atherosclerotic Peripheral Vascular Disease Working Group; Quality of Care Outcomes in Research Interdisciplinary Working Group. Guidelines for the early management of adults with ischemic stroke: a guideline from the American Heart Association/American Stroke Association Stroke Council, Clinical Cardiology Council, Cardiovascular Radiology and Intervention Council, and the Atherosclerotic Peripheral Vascular Disease and Quality of Care Outcomes in Research Interdisciplinary Working Groups: The American Academy of Neurology affirms the value of this guideline as an educational tool for neurologists. Circulation 2007;115(20):e478-e534

34 Ickenstein GW, Riecker A, Höhlig C, et al. Pneumonia and inhospital mortality in the context of neurogenic oropharyngeal dysphagia (NOD) in stroke and a new NOD step-wise concept. J Neurol 2010;257(09):1492-1499 
35 Wohns RN, Tamas L, Pierce KR, Howe JF. Chlorpromazine treatment for neurogenic pulmonary edema. Crit Care Med 1985;13 (03):210-211

36 Lord JM, Midwinter MJ, Chen YF, et al. The systemic immune response to trauma: an overview of pathophysiology and treatment. Lancet 2014;384(9952):1455-1465

37 Cengiz SL, Kalkan E, Bayir A, Ilik K, Basefer A. Timing of thoracolomber spine stabilization in trauma patients; impact on neurological outcome and clinical course. A real prospective (rct) randomized controlled study. Arch Orthop Trauma Surg 2008; 128(09):959-966

38 Furlan JC, Noonan V, Cadotte DW, Fehlings MG. Timing of decompressive surgery of spinal cord after traumatic spinal cord injury: an evidence-based examination of pre-clinical and clinical studies. J Neurotrauma 2011;28(08):1371-1399
39 Fouad $\mathrm{K}$, Tse A. Adaptive changes in the injured spinal cord and their role in promoting functional recovery. Neurol Res 2008;30(01):17-27 40 Onifer SM, Smith GM, Fouad K. Plasticity after spinal cord injury: relevance to recovery and approaches to facilitate it. Neurotherapeutics 2011;8(02):283-293

41 Bracken MB, Shepard MJ, Collins WF, et al. A randomized, controlled trial of methylprednisolone or naloxone in the treatment of acute spinal-cord injury. Results of the Second National Acute Spinal Cord Injury Study. N Engl J Med 1990;322(20):1405-1411

42 Kwon BK, Okon E, Hillyer J, et al. A systematic review of noninvasive pharmacologic neuroprotective treatments for acute spinal cord injury. J Neurotrauma 2011;28(08):1545-1588

43 Wang J, Pearse DD. Therapeutic hypothermia in spinal cord injury: the status of its use and open questions. Int J Mol Sci 2015;16(08):16848-16879 